\title{
Malaria knowledge and bed net use in three transmission settings in southern Africa
}

\author{
Mufaro Kanyangarara ${ }^{*}$ (D), Harry Hamapumbu², Edmore Mamini ${ }^{3}$, James Lupiya ${ }^{4}$, Jennifer C. Stevenson ${ }^{2,5}$, \\ Sungano Mharakurwa ${ }^{3}$, Mike Chaponda ${ }^{4}$, Philip E. Thuma ${ }^{2,5}$, Lovemore Gwanzura ${ }^{6}$, Shungu Munyati ${ }^{3}$, \\ Modest Mulenga ${ }^{4}$, Douglas E. Norris ${ }^{5}$, William J. Moss ${ }^{5,7}$ and For the Southern Africa International Centers of \\ Excellence for Malaria Research
}

\begin{abstract}
Background: Insecticide-treated nets (ITNs) reduce malaria morbidity and mortality in endemic areas. Despite increasing availability, the use of ITNs remains limited in some settings. Poor malaria knowledge is a barrier to the widespread use of ITNs. The goal of this study was to assess the levels of malaria knowledge and evaluate factors associated with bed net use among individuals residing in three regions of southern Africa with different levels of malaria transmission and control.

Methods: A cross-sectional study was conducted on a sample of 7535 residents recruited from 2066 households in Mutasa District, Zimbabwe (seasonal malaria transmission), Choma District, Zambia (low transmission) and Nchelenge District, Zambia (high transmission), between March 2012 and March 2017. A standardized questionnaire was used to collect data on demographics, malaria-related knowledge and use of preventive measures. Multivariate logistic regression analyses were used to assess determinants of bed net use.

Results: Most of the 3836 adult participants correctly linked mosquito bites to malaria (85.0\%), mentioned at least one malaria symptom (95.5\%) and knew of the benefit of sleeping under an ITN. Bed net ownership and use were highest in Choma and Nchelenge Districts and lowest in Mutasa District. In multivariate analyses, knowledge of ITNs was associated with a 30-40\% increased likelihood of bed net use after adjusting for potential confounders across all sites. Other factors significantly associated with bed net use were age, household size and socioeconomic status, although the direction, strength and size of association varied by study site. Importantly, participants aged 5-14 years had reduced odds of sleeping under a bed net compared to children younger than 5 years.

Conclusion: Relevant knowledge of ITNs translated into the expected preventive behaviour of sleeping under a bed net, underscoring the need for continued health messaging on malaria prevention. The implementation and delivery of malaria control and elimination interventions needs to consider socioeconomic equity gaps, and target school-age children to ensure access to and improve utilization of ITNs.
\end{abstract}

Keywords: Insecticide-treated nets, Local knowledge, Malaria prevention and control, Zambia, Zimbabwe

\section{Background}

Globally, immense efforts have been made to control malaria, with the goal to ultimately eliminate malaria transmission [1]. Insecticide-treated nets (ITNs) are an

\footnotetext{
*Correspondence: mkanyan1@jhu.edu

1 Department of International Health, Johns Hopkins Bloomberg School of Public Health, Baltimore, MD, USA

Full list of author information is available at the end of the article
}

important component of malaria control and elimination strategies. ITNs have been shown to reduce malaria episodes by $50 \%$ and under-five mortality by $17 \%$ [2]. Several studies from sub-Saharan Africa have also demonstrated community-wide benefits of ITNs on malariarelated morbidity and mortality $[3,4]$. Despite individual and community-wide benefits, ITN use remains below universal coverage. A significant determinant of ITN use is ITN ownership [5]. The increased access to ITNs but 
lagging ITN use underscores the role of human behaviour in malaria transmission, treatment and control [6]. Numerous individual, household and community factors have been identified as determinants of ITN possession and use, including age, gender, level of education, socioeconomic status, household size, use of other preventive methods, and malaria-related knowledge [7-10]. Malaria knowledge is an important factor in the design and implementation of malaria control programmes. Several studies assessing the distribution of malaria knowledge in sub-Saharan Africa demonstrated inconsistent levels of malaria knowledge and indicated that misconceptions concerning the etiology and prevention of malaria still exist [11-18]. According to existing theories of health behaviour change, high levels of knowledge about the causation, transmission, prevention and treatment of malaria may facilitate changes in attitude, resulting in the adoption of positive preventive practices that reduce the risk of exposure to malaria and contribute to decreased malaria transmission [19].

The specific contribution of malaria knowledge to the adoption of malaria preventive behaviours is complex, and the strength and magnitude of reported associations has varied widely by context. Greater understanding of the level of malaria knowledge and association with malaria preventive behaviours in different transmission settings is essential for the implementation of evidencebased strategies to accelerate progress towards malaria elimination. The objectives of this study were to assess the underlying levels of malaria knowledge and evaluate the independent influence of malaria knowledge on bed net use in three settings in southern Africa with varying levels of malaria transmission and control. Findings will inform the development and targeting of context specific strategies to support and strengthen ongoing programmes to reduce malaria-related mortality and morbidity in southern Africa.

\section{Methods \\ Study sites}

The study was based on a sample of 7535 participants representing 2066 randomly selected households from Mutasa District in eastern Zimbabwe, Choma District in southern Zambia and Nchelenge District in northern Zambia. The data used were acquired under the auspices of the Southern and Central Africa International Centers of Excellence for Malaria Research (ICEMR) project. The three study sites were specifically chosen by the Southern and Central Africa ICEMR to highlight variability in the epidemiology and transmission of malaria across southern Africa (Fig. 1, Table 1). In Choma District, malaria transmission is seasonal and the prevalence of malaria is low. By contrast, in Nchelenge District, which lies along
Lake Mweru and borders the Democratic Republic of Congo, malaria transmission is intense with little or no seasonal fluctuations. Malaria transmission in Mutasa District is highly seasonal, with malaria-related morbidity and mortality peaking during the rainy season.

Several malaria control activities including the distribution of ITNs and application of indoor residual spraying (IRS) occurred during the study period (Fig. 2). In Choma District, mass distribution of free, long-lasting insecticidal nets (LLINs) occurred in 2007, 2012 and 2014 [7, 20]. In Nchelenge District, mass LLIN distribution campaigns took place in 2007, 2011 and 2014. Annual rounds of IRS began in 2006, first with pyrethroids, then carbamates [21]. Since 2014, the organophosphate pirimiphos-methyl has been used for targeted IRS in the study area. Similar to Nchelenge District, there was a programmatic switch from pyrethroid-based to organophosphate-based IRS in Mutasa District in 2014. Following the introduction of pirimiphos-methyl, Mutasa District has experienced moderate reductions in malaria incidence [22]. Universal ITN distribution to the general population was conducted in 2013, with distributions to vulnerable populations (e.g. school age children) in 2014 and 2015.

\section{Study design and procedures}

The study design and procedures have been described elsewhere [23-25]. Briefly, high resolution satellite images of the study areas were used to establish sampling frames and study households were randomly selected for enrolment in the cross-sectional study arm or the prospective longitudinal cohort. Households enrolled in the longitudinal cohort were visited every other month, while households in the cross-sectional arm were surveyed only once during the study period. Study enrollment began in March 2012 in Choma District, April 2012 in Nchelenge District and October 2012 in Mutasa District (Fig. 2). Across all sites, cross-sectional surveys and longitudinal surveys were conducted during alternating months during the study period. Enrollment of new participants from randomly selected households in Choma District ended in December 2014; thereafter, participants have been recruited under the reactive test and treat programme [26]. Study enrollment is still ongoing in the other sites. For the purposes of this analysis, December 31, 2015 was set as the cutoff date for Choma District and March 31, 2017 for Nchelenge and Mutasa Districts. The analysis was restricted to data from all visits in the crosssectional arm and the initial baseline visits for the longitudinal cohort.

Data were collected using standardized data collection instruments that were field tested to ensure reliability and validity. In all selected households, the head 

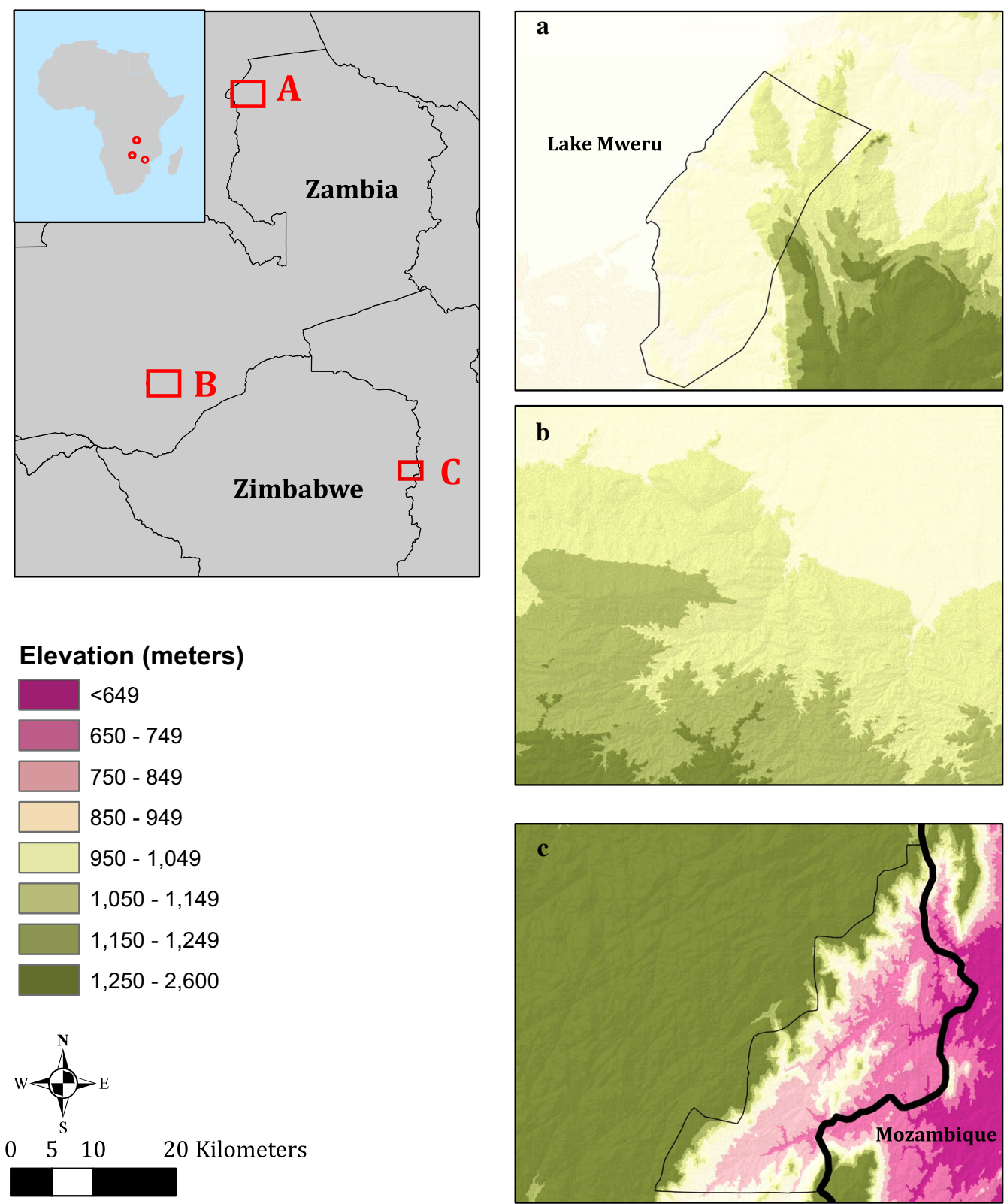

Fig. 1 Location of Southern Africa International Centers of Excellence for Malaria Research study sites: a Nchelenge District, Zambia. b Choma District, Zambia. c Mutasa District, Zimbabwe

or another responsible adult member of the household was interviewed after informed consent was given. A complete listing of all residents of selected households was obtained and all residents were eligible to participate regardless of age, gender or pregnancy status. The availability of household assets and characteristics of the house structure were recorded. An interviewer-administered questionnaire was used to gather data on malaria-specific knowledge for adult participants and presenting symptoms, health-seeking behaviours and malaria prevention practices for all participants. At the end of each interview, a blood sample was collected for a malaria rapid diagnostic test (RDT). Participants with positive test results were treated as per the country-specific malaria treatment guidelines.

\section{Measures}

Several measures reflecting population coverage of bed nets were calculated as recommended by the Roll Back Malaria (RBM) partnership [5, 27], using data 


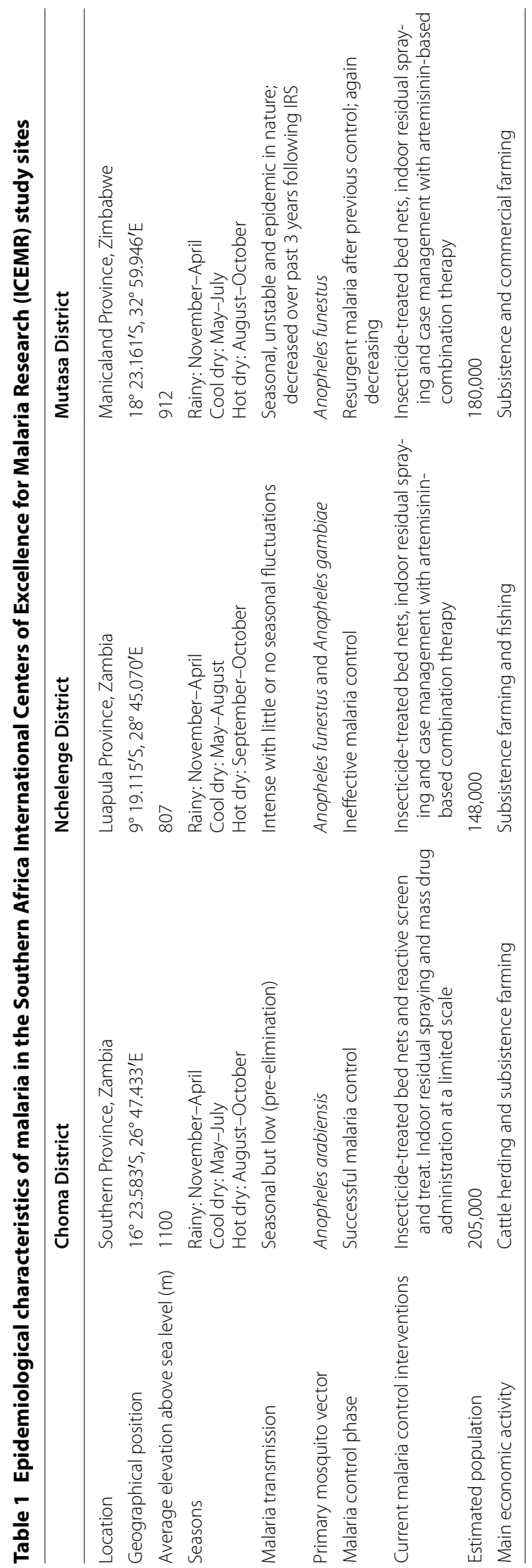




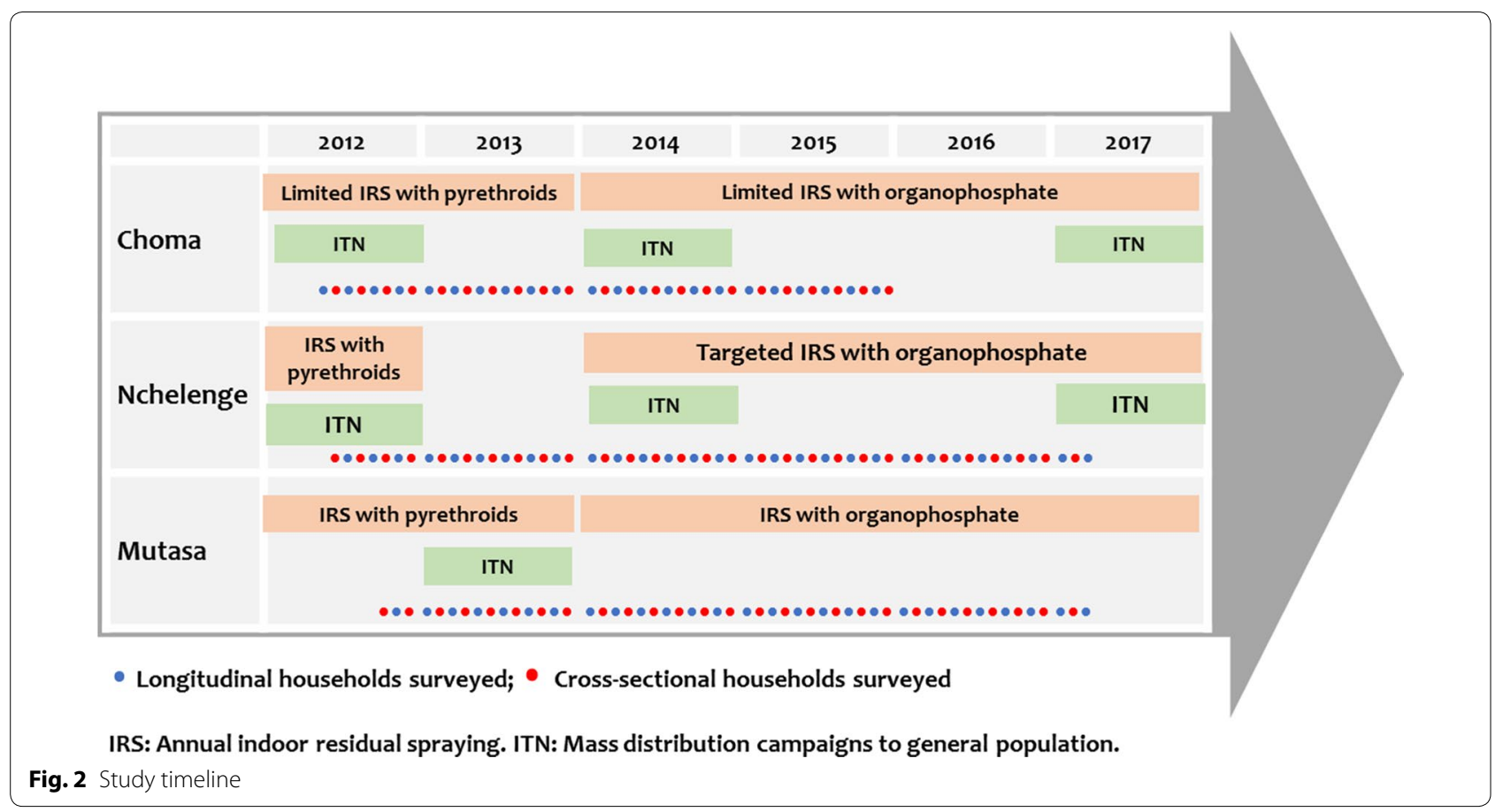

on direct observation of bed net ownership and selfreported bed net use. The term 'bed net' was used to encompass insecticide-treated and untreated bed nets, although long-lasting insecticidal nets (LLINs) are the standard in all study sites. The primary outcome measure was individual-level bed net use among those with living in a household with any bed net. The primary exposure of interest was knowledge of the benefit of sleeping under an ITN derived from responses to an unprompted open-ended question on the ways to prevent malaria. Demographic characteristics included gender and age of the respondent $(<5,5-14,15-34$, and $\geq 35$ years $)$. Three variables, namely, educational level of the head of the household (none or primary, secondary education and tertiary education or higher), permanent employment status of the head of the household (employed or unemployed) and a wealth index, were used as proxies for socioeconomic status. The wealth index was calculated using principal components analysis based on ownership of assets (radio, television, refrigerator, bicycle, motorcycle, and car or truck) and house characteristics (source of drinking water, source of energy for cooking and floor material) [28]. The index was divided into three tertiles-'poorest', 'less poor' and 'least poor'. Other variables controlled for in the analysis were based on prior literature and included number of children under 5 years, number of bed nets in household, and household size.

\section{Analysis}

Frequency distributions were used to describe the sample population, quantify knowledge about the cause, symptoms and prevention measures for malaria, and describe bed net ownership and use. Pearson's Chi squared test was used to compare sociodemographic and household characteristics across study sites. To determine if knowledge of ITNs as a preventive measure significantly increased the odds of bed net use, logistic regression analyses were performed separately for each study site. To account for within-household correlation, univariate and multivariate logistic regression analyses were conducted using generalized estimated equations (GEE) [29]. Age and gender were included in all multivariate models to control for potential confounding. Calendar year and season (rainy/dry) were also included to account for secular trends and seasonality in the outcomes. Adjusted odds ratios (aOR) with 95\% confidence intervals (CI) were computed from the final GEE models. A $p$ value of less than 0.05 was considered statistically significant. Analyses were performed using STATA 14.2 (College Station, Texas).

\section{Results}

\section{Characteristics of the study population}

The analysis included 7535 participants, with 1761 from Choma District, 3405 from Nchelenge District and 2369 from Mutasa District (Table 2). One in five participants was under 5 years of age (19.3\%), and slightly more than 
Table 2 Study population characteristics by study site

\begin{tabular}{|c|c|c|c|c|c|c|c|c|c|}
\hline \multirow[t]{2}{*}{ Variables } & \multicolumn{2}{|c|}{$\begin{array}{l}\text { Choma District } \\
\mathrm{N}=1761\end{array}$} & \multicolumn{2}{|c|}{$\begin{array}{l}\text { Nchelenge } \\
\text { District } \\
\mathrm{N}=3405\end{array}$} & \multicolumn{2}{|c|}{$\begin{array}{l}\text { Mutasa District } \\
N=2369\end{array}$} & \multicolumn{2}{|c|}{$\begin{array}{l}\text { Total } \\
\mathrm{N}=7535\end{array}$} & \multirow[t]{2}{*}{$p_{\text {value }}{ }^{a}$} \\
\hline & $\mathbf{n}$ & $\%$ & $\mathrm{n}$ & $\%$ & $\mathrm{n}$ & $\%$ & $\mathrm{n}$ & $\%$ & \\
\hline Age (years) & & & & & & & & & $<0.001$ \\
\hline$<5$ & 383 & 21.8 & 670 & 19.7 & 402 & 17.0 & 1455 & 19.3 & \\
\hline $5-14$ & 541 & 30.7 & 1022 & 30.0 & 533 & 22.5 & 2096 & 27.8 & \\
\hline $15-34$ & 432 & 24.5 & 955 & 28.1 & 742 & 31.3 & 2129 & 28.3 & \\
\hline$\geq 35$ & 405 & 23.0 & 758 & 22.3 & 692 & 29.2 & 1855 & 24.6 & \\
\hline Gender & & & & & & & & & 0.21 \\
\hline Male & 810 & 46.0 & 1530 & 44.9 & 1026 & 43.3 & 3366 & 44.7 & \\
\hline Female & 951 & 54.0 & 1875 & 55.1 & 1343 & 56.7 & 4169 & 55.3 & \\
\hline Education level of head of household & & & & & & & & & $<0.001$ \\
\hline Primary or less & 990 & 56.2 & 2329 & 68.4 & 1051 & 44.4 & 4370 & 58.0 & \\
\hline Secondary & 709 & 40.3 & 1025 & 30.1 & 1112 & 46.9 & 2846 & 37.8 & \\
\hline Tertiary & 62 & 3.5 & 51 & 1.5 & 206 & 8.7 & 319 & 4.2 & \\
\hline Employment status of head of household & & & & & & & & & $<0.001$ \\
\hline Employed & 132 & 7.5 & 229 & 6.7 & 1102 & 46.5 & 1463 & 19.4 & \\
\hline Unemployed & 1629 & 92.5 & 3172 & 93.3 & 1267 & 53.5 & 6068 & 80.6 & \\
\hline \multicolumn{10}{|l|}{ Household asset ownership } \\
\hline Radio & 1286 & 73.1 & 2190 & 64.3 & 1281 & 53.9 & 4757 & 63.1 & $<0.001$ \\
\hline Television & 480 & 27.3 & 242 & 7.1 & 670 & 28.2 & 1392 & 18.5 & $<0.001$ \\
\hline Fridge & 24 & 1.4 & 57 & 1.7 & 185 & 7.8 & 266 & 3.5 & $<0.001$ \\
\hline Bicycle & 1353 & 76.9 & 2391 & 70.2 & 634 & 26.7 & 4378 & 58.1 & $<0.001$ \\
\hline Motorcycle & 37 & 2.1 & 28 & 0.8 & 85 & 3.6 & 150 & 2.0 & $<0.001$ \\
\hline Car or truck & 136 & 7.7 & 5 & 0.1 & 212 & 8.9 & 353 & 4.7 & $<0.001$ \\
\hline Source of drinking water: piped water & 16 & 2.0 & 17 & 1.0 & 390 & 28.0 & 423 & 11.1 & $<0.001$ \\
\hline Source of energy for cooking: electricity & 4 & 0.5 & 22 & 1.3 & 104 & 7.5 & 130 & 3.4 & $<0.001$ \\
\hline Main material of floor: finished flooring & 225 & 28.5 & 209 & 12.9 & 1229 & 88.4 & 1662 & 43.7 & $<0.001$ \\
\hline Number of household members & & & & & & & & & $<0.001$ \\
\hline $1-2$ & 93 & 5.3 & 596 & 17.5 & 454 & 19.2 & 1143 & 15.2 & \\
\hline $3-6$ & 846 & 48.0 & 2235 & 65.6 & 1259 & 53.1 & 4340 & 57.6 & \\
\hline$\geq 7$ & 822 & 46.7 & 574 & 16.9 & 656 & 27.7 & 2052 & 27.2 & \\
\hline Visited health facility for malaria in past 6 months & 238 & 13.5 & 1906 & 56.0 & 687 & 28.9 & 2831 & 37.6 & $<0.001$ \\
\hline Visited health facility for malaria in past month & 32 & 1.8 & 791 & 23.2 & 247 & 10.4 & 1070 & 14.2 & $<0.001$ \\
\hline
\end{tabular}

a Chi squared test

half of participants were female (55.3\%). There were some differences in sociodemographic characteristics by study site. Compared to the other study sites, participants in Choma District tended to reside in larger households, with $46.7 \%$ of participants residing in a household with 7 or more members ( $\mathrm{p}<0.001)$. Compared to Choma and Nchelenge Districts, a higher proportion of participants in Mutasa District belonged to households headed by individuals who had completed secondary or tertiary education $(55.6 \%, \mathrm{p}<0.001)$ and were in permanent employment $(46.5 \%, \mathrm{p}<0.001)$. Participants from Mutasa District were also relatively better off than their counterparts as a higher proportion of participants reported the use of electricity for cooking $(7.5 \%, \mathrm{p}<0.001)$, piped water for drinking $(28.0 \%, \mathrm{p}<0.001)$ and a finished floor in the home $(88.4 \%, \mathrm{p}<0.001)$. A higher proportion of participants in Mutasa District lived in households that had been covered by IRS in the previous 6 months than the two Zambian sites $(40.5 \%, \mathrm{p}<0.001)$.

\section{Malaria-related knowledge}

Of the 3843 participants aged 16 years or older and eligible to respond to questions related to malaria knowledge, 3836 (99.9\%) responded to the malaria knowledge questionnaire (Table 3). The majority $(85.0 \%)$ of respondents linked malaria to a mosquito bite, with the highest 
Table 3 Reported knowledge on malaria causes, symptoms and preventive measures by study site

\begin{tabular}{|c|c|c|c|c|c|c|c|c|}
\hline & \multicolumn{2}{|c|}{$\begin{array}{l}\text { Choma District } \\
\mathrm{N}=789\end{array}$} & \multicolumn{2}{|c|}{$\begin{array}{l}\text { Nchelenge District } \\
\mathrm{N}=1643\end{array}$} & \multicolumn{2}{|c|}{$\begin{array}{l}\text { Mutasa District } \\
\mathrm{N}=1404 \\
\end{array}$} & \multicolumn{2}{|c|}{$\begin{array}{l}\text { Total } \\
\mathrm{N}=3836\end{array}$} \\
\hline & $\mathrm{n}$ & $\%$ & $\mathbf{n}$ & $\%$ & $\mathbf{n}$ & $\%$ & $\mathbf{n}$ & $\%$ \\
\hline \multicolumn{9}{|l|}{ Knowledge of causes of malaria } \\
\hline Mosquito bites & 705 & 89.4 & 1344 & 81.8 & 1212 & 86.3 & 3261 & 85.0 \\
\hline Also cited other cause(s) & 48 & 6.8 & 21 & 1.6 & 19 & 1.6 & 88 & 2.7 \\
\hline Dirty surroundings & 72 & 9.1 & 24 & 1.5 & 54 & 3.8 & 150 & 3.9 \\
\hline Drinking bad water & 80 & 10.1 & 36 & 2.2 & 21 & 1.5 & 137 & 3.6 \\
\hline Other causes $^{\mathrm{a}}$ & 57 & 7.2 & 38 & 2.3 & 62 & 4.4 & 157 & 4.1 \\
\hline \multicolumn{9}{|l|}{ Knowledge of malaria symptoms } \\
\hline Mentioned 3 or more common symptoms of malariab & 264 & 33.5 & 267 & 16.3 & 583 & 15.2 & 1114 & 29.0 \\
\hline Chills & 490 & 62.1 & 925 & 56.3 & 708 & 50.5 & 2123 & 55.4 \\
\hline Headache & 539 & 68.3 & 491 & 29.9 & 982 & 70.0 & 2012 & 52.5 \\
\hline Fever & 374 & 47.4 & 588 & 35.8 & 476 & 33.9 & 1438 & 37.5 \\
\hline Weakness or fatigue & 159 & 20.2 & 188 & 11.4 & 845 & 60.2 & 1192 & 31.1 \\
\hline Body ache or pain & 157 & 19.9 & 542 & 33.0 & 209 & 14.9 & 908 & 23.7 \\
\hline Vomiting & 243 & 30.8 & 94 & 5.7 & 499 & 35.6 & 836 & 21.8 \\
\hline Other symptoms ${ }^{c}$ & 374 & 47.4 & 248 & 15.1 & 569 & 40.5 & 1191 & 31.0 \\
\hline \multicolumn{9}{|l|}{ Knowledge of the prevention of malaria } \\
\hline Sleep under a mosquito net & 689 & 87.3 & 1173 & 71.4 & 943 & 67.2 & 2805 & 73.1 \\
\hline Seek early treatment & 134 & 17.0 & 145 & 8.8 & 161 & 11.5 & 440 & 11.5 \\
\hline Keep surroundings clean & 113 & 14.3 & 49 & 3.0 & 257 & 18.3 & 419 & 10.9 \\
\hline Bury mosquito breeding sites & 84 & 10.6 & 36 & 2.2 & 203 & 14.5 & 323 & 8.4 \\
\hline Spray insecticide inside the house & 23 & 2.9 & 24 & 1.5 & 211 & 15.0 & 258 & 6.7 \\
\hline Take medicine to prevent malaria & 10 & 1.3 & 87 & 5.3 & 91 & 6.5 & 188 & 4.9 \\
\hline Eat clean food & 80 & 10.1 & 34 & 2.1 & 27 & 1.9 & 141 & 3.7 \\
\hline Other measures $^{d}$ & 10 & 1.3 & 34 & 2.1 & 180 & 12.8 & 224 & 5.8 \\
\hline \multicolumn{9}{|l|}{ Source of malaria knowledge } \\
\hline Health care worker at clinic or hospital & 539 & 68.3 & 754 & 45.9 & 793 & 56.5 & 2086 & 54.4 \\
\hline School & 110 & 13.9 & 243 & 14.8 & 248 & 17.7 & 601 & 15.7 \\
\hline Community health worker & 32 & 4.1 & 76 & 4.6 & 223 & 15.9 & 331 & 8.6 \\
\hline Other sources ${ }^{e}$ & 88 & 11.2 & 224 & 13.6 & 131 & 9.3 & 443 & 11.5 \\
\hline
\end{tabular}

Percentage total exceed 100 because of multiple responses

a Other causes included breathing bad air, cold related and eating bad food, fresh fruits, maize or sugar cane

b Common symptoms of malaria were fever, chills, headache, weakness or fatigue, and body ache or pain

c Other symptoms included diarrhea, coughing, flu-like symptoms, yellow eyes or skin and thirst

d Other preventive measures included keeping the skin covered, wearing insect repellent, having screens on the windows, burning mosquito coils, burning a fire in the house and not going outside at certain times

e Other sources were radio, newspapers, posters in health post or health center, friends or relatives, non-governmental organizations and the ICEMR study team

proportion (89.4\%) in Choma District, the setting with the lowest malaria burden. A few respondents associated malaria with dirty surroundings (3.9\%), drinking bad water (3.6\%), and other causes including eating bad food, fresh fruit, maize or sugar cane (4.1\%). Among those who correctly linked malaria to a mosquito bite, $2.7 \%$ also cited one or more incorrect causes. The most frequent symptoms listed as presumptive for malaria varied by site. In Choma District, respondents most commonly associated malaria with headache $(68.3 \%)$, chills $(62.1 \%)$ and fever (47.4\%). In Nchelenge District, chills (56.3\%), fever (35.8\%) and body ache or pain (33.0\%) were the most commonly reported symptoms of malaria. By contrast, headaches $(70.0 \%)$, weakness or fatigue $(60.2 \%)$ and chills $(50.5 \%)$ were the most commonly reported symptoms in Mutasa District. Overall, almost all respondents (95.5\%) mentioned at least one common symptom of malaria (fever, chills, headache, weakness or fatigue, and body ache or pain), and $29.0 \%$ could mention three or more of the common symptoms of malaria. Sleeping 
under a mosquito net was the most commonly reported measure thought to prevent malaria $(73.1 \%)$, with the highest level of knowledge of the benefits of net use in Choma District (87.3\%) and the lowest in Mutasa District (67.2\%). Seeking early treatment (11.5\%), keeping surroundings clean (10.9\%), burying mosquito breeding sites $(8.34 \%)$ and indoor residual spraying (6.7\%) were other preventive measures reported. A minority of respondents linked eating clean food to the prevention of malaria (3.7\%). Information about malaria was commonly received from health workers in health facilities (54.4\%), schools (15.7\%), and the community (8.6\%). Less frequently mentioned sources of information about malaria were radios, newspapers, posters, friends, relatives, nongovernmental organizations and the study team.

\section{Bed net ownership, access and use}

Bed net ownership, access and use varied by study site, with Mutasa District reporting the lowest levels. At the household level, ownership of any bed net was 69.9\%, while ownership of sufficient bed nets (i.e. at least one bed net for every two members) was 39.7\% (Table 4). At the population level, access to a bed net within the household was $39.2 \%$, while bed net use was $31.8 \%$. The proportion of the population using bed nets was fairly similar to the proportion of the population with access to a bed net, indicating an average of two users per net. Unavailability of bed nets (50\%) and the perceived lack of mosquitoes $(26.5 \%)$ were the main reasons reported by households for not owning a net, while the perceived lack of mosquitoes $(17.4 \%)$ and heat (10.1\%) were the main reasons for not sleeping under a bed net. By contrast, in the low transmission setting of Choma District, $78.2 \%$ of household owned any bed net and $70.8 \%$ of the population reported sleeping under a bed net. Indicators of bed net ownership, access and use for Nchelenge District did not vary appreciably from Choma District despite the higher malaria transmission intensity. In both Zambian

Table 4 Bed net ownership, access and use by study site

\begin{tabular}{|c|c|c|c|c|}
\hline & Choma District & Nchelenge District & Mutasa District & Total \\
\hline Population with access to an ITN within their household (\%) & 70.8 & 57.8 & 39.2 & 55.0 \\
\hline Population that slept under an ITN (\%) & 55.6 & 57.4 & 31.8 & 49.0 \\
\hline Children under 5 years old who slept under an ITN (\%) & 60.8 & 59.7 & 34.9 & 53.2 \\
\hline Households with at least one ITN (\%) & 78.2 & 77.8 & 69.9 & 75.3 \\
\hline Households with at least one ITN for every two people (\%) & 49.6 & 49.0 & 39.7 & 46.0 \\
\hline Households sprayed in the last 6 months (\%) & 2.3 & 14.5 & 42.9 & 21.9 \\
\hline Households with at least one ITN and/or sprayed by IRS in the last 6 months (\%) & 79.0 & 80.7 & 81.8 & 80.8 \\
\hline $\begin{array}{l}\text { Households with at least one ITN for every two people and/or sprayed by IRS within } \\
\text { the last } 6 \text { months (\%) }\end{array}$ & 51.6 & 55.9 & 64.7 & 58.1 \\
\hline \multicolumn{5}{|l|}{ Reasons for not owning a bed net at the household level ${ }^{a}$} \\
\hline Nets not available & 7.0 & 26.1 & 50.5 & 31.3 \\
\hline No mosquitoes & 16.8 & 19.8 & 26.5 & 21.7 \\
\hline Too expensive & 32.1 & 26.9 & 2.3 & 18.8 \\
\hline Don't know where to get a bed net & 22.5 & 21.6 & 0 & 13.7 \\
\hline Heat & 3.5 & 0.6 & 3.4 & 2.2 \\
\hline Other reasons ${ }^{a}$ & 10.8 & 1.4 & 7.0 & 5.5 \\
\hline \multicolumn{5}{|l|}{ Reasons for not sleeping under an available bed net at the individual level ${ }^{b}$} \\
\hline Heat & 3.2 & 1.0 & 10.1 & 5.5 \\
\hline Net is old, dirty or needs to be retreated & 0.4 & 4.8 & 2.7 & 3.0 \\
\hline Not enough bed nets & 2.8 & 1.1 & 0.2 & 1.0 \\
\hline Does not protect against mosquitoes & 3.9 & 0 & 0 & 0.8 \\
\hline Lack of mosquitoes & 5.2 & 0.5 & 17.4 & 9.0 \\
\hline Unable to hang over sleeping space & 0.6 & 0.9 & 2.9 & 1.7 \\
\hline Net is itchy & 1.7 & 0.1 & 1.4 & 1.0 \\
\hline Other reasons ${ }^{b}$ & 0.6 & 0.9 & 0.3 & 0.6 \\
\hline
\end{tabular}

Percentage total exceed 100 because of multiple responses

a Other reasons for not owning a bed net included lack of protection against mosquitoes, nets only for children and pregnant women, not the rainy or malaria season and sleeping space is outside or changes too often

b Other reasons for not sleeping under an available bed net included not the rainy or malaria season, keeping nets for children and pregnant women, sleeping space is outside, and frequent changes to sleeping place 
sites, cost and lack of knowledge of where to obtain a bed net were the main barriers to bed net ownership reported (Choma: 32.1 and 22.5\% respectively; Nchelenge: 26.7 and $21.6 \%$ respectively). However, the perceived lack of mosquitoes (5.2\%) was the most cited reason for non-use of available bed nets in Choma District, while the most common reason in Nchelenge District was the state of the available net (old, dirty or in need of retreatment; $4.8 \%)$.

\section{Factors associated with bed net use}

In Choma District, multivariate analyses restricted to individuals residing in households with any bed nets demonstrated marginal evidence of a higher odds of bed net use among respondents with knowledge of ITNs as a preventive measure (aOR 1.40, 95\% CI 0.97-2.03) (Table 5 ). Compared to individuals aged less than 5 years, the odds of bed net use were greater in the $\geq 35$ years age group (aOR 2.38; 95\% CI 1.55-3.67) and lesser in the 5-14 years age group (aOR 0.57; 95\% CI 0.41-0.79). The odds of bed net use decreased with large household size (3-6 members: aOR 0.29; 95\% CI 0.14-0.58; 7+ members: aOR 0.32; $95 \% \mathrm{CI} 0.16-0.67$ relative to one to two members). Also, residing in a household with three or more bed nets or with at least one child under 5 years increased the odds of bed net use (aOR 2.52; 95\% CI 1.75-3.62; aOR 1.42; 95\% CI 1.05-1.96, respectively).
Consistent with patterns observed among residents of Choma District, in Nchelenge District awareness of ITNs as a preventive measure was associated with statistically significant increased odds of bed net use (aOR 1.35; 95\% CI 1.11-1.64). Associations with bed net use of similar magnitude and significance were observed for age, household size, the presence of at least one child under 5 years and household ownership of three or more bed nets. However, the odds of bed net use were significantly higher among females (aOR 1.34; 95\% CI 1.11-1.61) and individuals from households of higher socio-economic status (least poor aOR 1.56; 95\% CI 1.19-2.06).

Knowledge of ITNs was predictive of bed net use in Mutasa District (aOR 1.27; 95\% CI 1.02-1.58). Age was associated with bed net use, with the odds of bed net use significantly higher among respondents 35 years or older (aOR 1.81; 95\% CI 1.18-2.79). The odds of bed net use were reduced by $26 \%$ among individuals residing in the least poor households compared to the poorest households (aOR 0.74; 95\% CI 0.57-0.96). The presence of at least three bed nets in the household increased the odds of bed net use by $93 \%$ (aOR 1.93; 95\% CI 1.37-2.72).

\section{Discussion}

This study assessed levels of malaria knowledge and factors associated with bed net use in three different transmission settings in Mutasa District, Zimbabwe,

Table 5 Factors associated with bed net use by study site

\begin{tabular}{|c|c|c|c|c|c|c|}
\hline & \multicolumn{2}{|l|}{$\begin{array}{l}\text { Choma District } \\
N=1446\end{array}$} & \multicolumn{2}{|c|}{$\begin{array}{l}\text { Nchelenge District } \\
N=2774\end{array}$} & \multicolumn{2}{|l|}{$\begin{array}{l}\text { Mutasa District } \\
\mathrm{N}=1803\end{array}$} \\
\hline & aOR $(95 \% \mathrm{Cl})$ & $p$ & aOR $(95 \% \mathrm{CI})$ & $\mathbf{p}$ & aOR (95\% CI) & $\mathrm{p}$ \\
\hline \multicolumn{7}{|l|}{ Age (years) } \\
\hline$<5$ & Reference & & Reference & & Reference & \\
\hline $5-14$ & $0.57(0.41-0.79)$ & 0.001 & $0.49(0.38-0.62)$ & $<0.001$ & $0.76(0.54-1.06)$ & 0.1 \\
\hline $15-34$ & $1.20(0.81-1.78)$ & 0.4 & $1.34(0.89-2.00)$ & 0.2 & $1.16(0.76-1.78)$ & 0.5 \\
\hline$\geq 35$ & $2.38(1.55-3.67)$ & $<0.001$ & $3.99(2.57-6.20)$ & $<0.001$ & $1.81(1.18-2.79)$ & 0.007 \\
\hline Female gender & $1.05(0.84-1.33)$ & 0.7 & $1.34(1.11-1.61)$ & 0.001 & $0.89(0.73-1.09)$ & 0.3 \\
\hline Has knowledge of ITNs & $1.40(0.97-2.03)$ & 0.07 & $1.35(1.11-1.64)$ & 0.003 & $1.27(1.02-1.58)$ & 0.03 \\
\hline \multicolumn{7}{|l|}{ Household wealth tertile } \\
\hline Poorest & Reference & & Reference & & Reference & \\
\hline Less poor & $1.16(0.87-1.56)$ & 0.3 & $1.46(1.20-1.78)$ & $<0.001$ & $1.03(0.77-1.40)$ & 0.8 \\
\hline Least poor & $1.06(0.78-1.44)$ & 0.7 & $1.56(1.19-2.06)$ & 0.001 & $0.74(0.57-0.96)$ & 0.02 \\
\hline \multicolumn{7}{|l|}{ Number of household members } \\
\hline $1-2$ & Reference & & Reference & & Reference & \\
\hline $3-6$ & $0.29(0.14-0.58)$ & 0.001 & $0.35(0.25-0.50)$ & $<0.001$ & $0.74(0.54-1.00)$ & 0.05 \\
\hline$\geq 7$ & $0.32(0.16-0.67)$ & 0.002 & $0.25(0.17-0.37)$ & $<0.001$ & $0.65(0.45-0.93)$ & 0.02 \\
\hline At least one child under 5 years in household & $1.43(1.05-1.96)$ & 0.03 & $1.70(1.35-2.14)$ & $<0.001$ & $1.26(0.98-1.61)$ & 0.07 \\
\hline Three or more bed nets in household & $2.52(1.75-3.62)$ & $<0.001$ & $1.42(0.99-2.04)$ & 0.06 & $1.93(1.37-2.72)$ & $<0.001$ \\
\hline
\end{tabular}

$a O R$ adjusted odds ratio, $\mathrm{Cl}$ confidence interval. Multivariate logistic regression model also included season and calendar year 
Choma District, Zambia and Nchelenge District, Zambia. In general, most respondents (85\%) knew the cause of malaria, albeit $2.7 \%$ of those also cited an incorrect cause of malaria. Most respondents (73.1\%) were aware of the protective benefit of sleeping under an ITN and could list at least one potential symptom of malaria (95.5\%). Similar levels of knowledge of the cause, prevention and symptoms of malaria were recently reported in other geographic areas in Zambia and Zimbabwe [7, 11, 18, 30-32]. These findings, in conjunction with recent improvements in the coverage of ITNs, highlight the success of malaria prevention education delivered by facility-based and community-based health workers, who were identified as the main source of malaria messages. However, our study suggests that some misconceptions still prevail. In Choma District, while 9 in 10 participants linked malaria to mosquito bites, about 1 in 10 residents still believed that drinking bad water causes malaria and 1 in 5 believed that dirty surroundings contribute to malaria. One explanation is that in this as well as other settings, the local term for 'malaria' is often used to describe fever and general malaise [15, 33]. Misconceptions and misinformation have continued amid intensified efforts to control and eliminate malaria. Ownership of a radio was common, yet less than $1 \%$ of participants reported hearing health messaging on malaria prevention through these mediums, representing a critical missed opportunity for the wider dissemination of health messaging to stimulate changes in knowledge and positive health behaviour change.

Across all transmission settings, the proportion of households with at least one bed net ranged from 69.9 to $78.2 \%$, but the proportion of households with at least one bed net per two members was substantially lower (range 39.7-49.6\%), suggesting a considerable intrahousehold ownership gap. These findings are consistent with national estimates of household bed net ownership rates from recent national surveys in Zimbabwe (60.3\%) and Zambia (79.5\%) [34, 35]. Notably, the lower ownership rates in Zimbabwe compared to Zambia may reflect national policy in Zimbabwe aimed at achieving universal malaria protection by deploying either ITNs or IRS, but not both, to malarious areas. This explanation is supported by the present study's finding that, while the proportion of households with any bed net was lower in Zimbabwe compared to the other sites, the proportion of households protected by bed nets or IRS or both was similar across the three sites.

In the present study, respondents who reported knowledge of the protective efficacy of ITNs had increased odds of sleeping under a bed net (up to 40\%). Results from this large community-based cross-sectional study are in concordance with other studies that demonstrated malaria knowledge is strongly associated with preventive behaviours related to malaria in sub-Saharan Africa [18, 32]. Associations were also found between bed net use and socioeconomic status, albeit with divergent directions of associations. For instance, in Nchelenge District, participants residing in the 'least poor' households had a greater likelihood of bed net use, compared to their counterparts of similar characteristics in the 'poorest' households. This finding was supported by the observation that the most cited reason for not owning a bed net in Nchelenge District was affordability. By contrast, in Mutasa District, increased household wealth was associated with a decreased odds of bed net use. The relatively lower use of ITNs in 'least poor' households might be a result of the lack of perceived vulnerability, as participants reported the lack of mosquitoes as a disincentive for bed net use. While associations with socio-economic status were heterogeneous across the three sites, these findings mirror reports of socioeconomic differentials in previous studies in sub-Saharan Africa, and most likely reflect the complex pathways that poverty influences malaria prevention practices [36]. However, regardless of the direction of the relationships, there is need for ITN distribution mechanisms and educational interventions that account for socio-economic differentials in ITN uptake and use. Our findings, in conjunction with those of previous studies, also strongly argue for the need to target individuals aged 5-14 years, who continue to emerge as a vulnerable population [7, 37, 38].

There are several limitations in interpreting the findings. First, given the cross-sectional nature of the data, causal associations between malaria knowledge and malaria prevention practices cannot be inferred. Second, the definition of the outcome, bed net use, was based on a question "Did you sleep under a bed net" which may not fully capture the temporal variations in bed net use. Furthermore, as the measure was based on self-report, it may have been subject to recall or social desirability bias. Third, the exposure of interest-knowledge of ITNs as a preventive measure-captures only one aspect of the broader concept of malaria knowledge and only one preventive measure. Fourth, the present study determined individual and household-level factors associated with bed net use; contextual factors such as country specific policies and implementation strategies may further explain bed net use. Furthermore, the primary objective of the broader community based survey was not to assess malaria knowledge, therefore, a limited number of open-ended questions specific to the cause, symptoms and prevention of malaria were selected to minimize response burden. Nevertheless, findings from this study give insights into the level of knowledge and the use of the same standardized questionnaire and indicator definitions 
allowed the examination of possible variations by study site. Further in-depth studies more appropriate methods such as knowledge, attitude, and practice (KAP) surveys and focus group discussions (FGDs) are warranted [39].

\section{Conclusions}

Knowledge of malaria in a large sample of residents in Zambia and Zimbabwe was good, and knowledge of the protective efficacy of ITNs was associated with bed net use. Other associations identified attest to the need for multipronged and context specific approaches to malaria prevention that simultaneously address social, cultural, and structural factors that drive malaria transmission. The considerably lower likelihood of bed net use in children 5-14 years was concerning. Promoting access to ITNs and malaria messaging for school age children should be considered an essential component of broader strategies to control and eliminate malaria in southern Africa and globally.

\begin{abstract}
Abbreviations
ACT: artemisinin-based combination therapy; aOR: adjusted odds ratio; $\mathrm{Cl}$ : confidence interval; GEE: generalized estimated equations; IRS: indoor residual spraying; ICEMR: International Centers for Excellence in Malaria Research; ITN: insecticide-treated mosquito net; LLIN: long-lasting insecticide-treated mosquito net; RDT: rapid diagnostic test.
\end{abstract}

\section{Authors' contributions}

MK performed the data analysis and drafted the manuscript. $\mathrm{HH}, \mathrm{EM}, \mathrm{JL}, \mathrm{JCS}$, SMharakurwa, MC, PET, LG, SMunyati, MM and DEN participated in the design and coordination of the study and reviewed the manuscript. WJM conceived of the study, participated in its design and coordination, and drafted the manuscript. All authors read and approved the final manuscript.

\section{Author details}

${ }^{1}$ Department of International Health, Johns Hopkins Bloomberg School of Public Health, Baltimore, MD, USA. ${ }^{2}$ Macha Research Trust, Macha, Choma District, Zambia. ${ }^{3}$ Biomedical Research and Training Institute, Harare, Zimbabwe. ${ }^{4}$ Tropical Disease Research Centre, Ndola Central Hospital, Ndola, Zambia. ${ }^{5}$ Department of Molecular Microbiology and Immunology, Johns Hopkins Bloomberg School of Public Health, Baltimore, MD, USA. ${ }^{6}$ Department of Medical Laboratory Sciences, University of Zimbabwe College of Health Sciences, Harare, Zimbabwe. ${ }^{7}$ Department of Epidemiology, Johns Hopkins Bloomberg School of Public Health, Baltimore, MD, USA.

\section{Acknowledgements}

The authors would like to thank the field teams and communities in Choma, Nchelenge and Mutasa Districts for their contributions. The Southern Africa International Centers of Excellence for Malaria Research includes the following institutions: Biomedical Research and Training Institute, Zimbabwe; Johns Hopkins Malaria Research Institute, USA; Macha Research Trust, Zambia; National Institute of Health Research, Zimbabwe; Tropical Diseases Research Centre, Zambia; University of the Witwatersrand, South Africa; and the University of Zambia, Zambia.

\section{Competing interests}

The authors declare that they have no competing interests.

\section{Availability of data and materials}

The datasets used in the present study are not publicly available to protect the confidentiality and privacy of study participants, but are available from the corresponding author upon appropriate reasonable request and approval from the corresponding national research and ethics committee.
Consent for publication

Not applicable.

\section{Ethics approval and consent to participate}

Ethical clearance and approval were obtained from the Institutional Review Boards of the Tropical Diseases Research Center in Zambia; the Biomedical Research and Training Institute in Zimbabwe, the Medical Research Council of Zimbabwe and the Johns Hopkins Bloomberg School of Public Health in Baltimore, Maryland. Local government officials were informed of the study purpose and procedures prior to data collection and local community acceptance was sought. Informed consent was obtained from all participants, and in the case of children, their caregivers.

\section{Funding}

This work was supported by the Johns Hopkins Malaria Research Institute, Bloomberg Philanthropies, and the Division of Microbiology and Infectious Diseases, National Institute of Allergy and Infectious Diseases as part of the International Centers of Excellence for Malaria Research (U19A1089680).

\section{Publisher's Note}

Springer Nature remains neutral with regard to jurisdictional claims in published maps and institutional affiliations.

Received: 18 August 2017 Accepted: 9 January 2018

Published online: 19 January 2018

\section{References}

1. World Health Organization. World malaria report. Geneva: World Health Organization; 2016

2. Lengeler $C$. Insecticide-treated bed nets and curtains for preventing malaria. Cochrane Database Syst Rev. 2004;2:CD000363.

3. Hawley WA, Phillips-Howard PA, ter Kuile FO, Terlouw DJ, Vulule JM, Ombok M, et al. Community-wide effects of permethrin-treated bed nets on child mortality and malaria morbidity in western Kenya. Am J Trop Med Hyg. 2003;68(4 Suppl):121-7.

4. Howard SC, Omumbo J, Nevill C, Some ES, Donnelly CA, Snow RW. Evidence for a mass community effect of insecticide-treated bednets on the incidence of malaria on the Kenyan coast. Trans R Soc Trop Med Hyg. 2000;94:357-60.

5. Koenker H, Kilian A. Recalculating the net use gap: a multi-country comparison of ITN use versus ITN access. PLoS ONE. 2014;9:1-7.

6. Korenromp EL, Miller J, Cibulskis RE, Kabir Cham M, Alnwick D, Dye C. Monitoring mosquito net coverage for malaria control in Africa: possession vs. use by children under 5 years. Trop Med Int Health. 2003;8:693-703.

7. Pinchoff J, Hamapumbu H, Kobayashi T, Simubali L, Stevenson JC, Norris DE, et al. Factors associated with sustained use of long-lasting insecticide-treated nets following a reduction in malaria transmission in southern Zambia. Am J Trop Med Hyg. 2015;93:954-60.

8. Baume CA, Franca-Koh AC. Predictors of mosquito net use in Ghana. Malar J. 2011;10:265.

9. Graves PM, Ngondi JM, Hwang J, Getachew A, Gebre T, Mosher AW, et al. Factors associated with mosquito net use by individuals in households owning nets in Ethiopia. Malar J. 2011;10:354.

10. Eisele TP, Keating J, Littrell M, Larsen D, Macintyre K. Assessment of insecticide-treated bednet use among children and pregnant women across 15 countries using standardized national surveys. Am J Trop Med Hyg. 2009;80:209-14.

11. Midzi N, Mtapuri-Zinyowera S, Mapingure MP, Paul NH, Sangweme D, Hlerema G, et al. Knowledge attitudes and practices of grade three primary schoolchildren in relation to schistosomiasis, soil transmitted helminthiasis and malaria in Zimbabwe. BMC Infect Dis. 2011;11:169.

12. Abate A, Degarege A, Erko B. Community knowledge, attitude and practice about malaria in a low endemic setting of Shewa Robit Town, northeastern Ethiopia. BMC Public Health. 2013;13:312. 
13. Mutua EN, Bukachi SA, Bett BK, Estambale BA, Nyamongo IK. Lay knowledge and management of malaria in Baringo county, Kenya. Malar J. 2016;15:486

14. Adongo PB, Kirkwood B, Kendall C. How local community knowledge about malaria affects insecticide-treated net use in northern Ghana. Trop Med Int Health. 2005;10:366-78.

15. O'Neill S, Gryseels C, Dierickx S, Mwesigwa J, Okebe J, d'Alessandro U, et al. Foul wind, spirits and witchcraft: illness conceptions and healthseeking behaviour for malaria in the Gambia. Malar J. 2015;14:167.

16. Njama D, Dorsey G, Guwatudde D, Kigonya K, Greenhouse B, Musisi S, et al. Urban malaria: primary caregivers'knowledge, attitudes, practices and predictors of malaria incidence in a cohort of Ugandan children. Trop Med Int Health. 2003;8:685-92.

17. Krezanoski PJ, Tsai AC, Hamer DH, Comfort AB, Bangsberg DR. Household malaria knowledge and its association with bednet ownership in settings without large-scale distribution programs: evidence from rural Madagascar. J Glob Health. 2014;4:10401.

18. Shimaponda-Mataa NM, Tembo-Mwase E, Gebreslasie M, Mukaratirwa S. Knowledge, attitudes and practices in the control and prevention of malaria in four endemic provinces of Zambia. S Afr J Infect Dis. 2017;32:29-39.

19. Panter-Brick C, Clarke SE, Lomas H, Pinder M, Lindsay SW. Culturally compelling strategies for behaviour change: a social ecology model and case study in malaria prevention. Soc Sci Med. 2006;62:2810-25.

20. Searle KM, Katowa B, Kobayashi T, Siame MNS, Mharakurwa S, Carpi G, et al. Distinct parasite populations infect individuals identified through passive and active case detection in a region of declining malaria transmission in southern Zambia. Malar J. 2017;16:154.

21. Mukonka VM, Chanda E, Haque U, Kamuliwo M, Mushinge G, Chileshe J, et al. High burden of malaria following scale-up of control interventions in Nchelenge District, Luapula Province, Zambia. Malar J. 2014;13:153.

22. Kanyangarara M, Mamini E, Mharakurwa S, Munyati S, Gwanzura L, Kobayashi $T$, et al. Reduction in malaria incidence following indoor residual spraying with actellic $300 \mathrm{cs}$ in a setting with pyrethroid resistance: Mutasa District, Zimbabwe. PLoS ONE. 2016;11:1-12.

23. Moss WJ, Dorsey G, Mueller I, Laufer MK, Krogstad DJ, Vinetz JM, et al. Malaria epidemiology and control within the International Centers of Excellence for Malaria Research. Am J Trop Med Hyg. 2015;93:5-15.

24. Moss WJ, Norris DE, Mharakurwa S, Scott A, Mulenga M, Mason PR, et al. Challenges and prospects for malaria elimination in the southern Africa region. Acta Trop. 2012;121:207-11.

25. Mharakurwa S, Thuma PE, Norris DE, Mulenga M, Chalwe V, Chipeta J, et al. Malaria epidemiology and control in southern Africa. Acta Trop. 2012:121:202-6.
26. Searle KM, Hamapumbu H, Lubinda J, Shields TM, Pinchoff J, Kobayashi T, et al. Evaluation of the operational challenges in implementing reactive screen-and-treat and implications of reactive case detection strategies for malaria elimination in a region of low transmission in southern Zambia. Malar J. 2016;15:412.

27. Measure DHS. Household survey indicators for malaria control. Measure evaluation. Geneva: World Health Organization; 2013.

28. Filmer D, Pritchett LH. Estimating wealth effects without expenditure data—or tears: an application to educational enrollments in states of India. Demography. 2001;38:115-32.

29. Zorn CJW. Generalized estimating equation models for correlated data: a review with applications. Am J Pol Sci. 2001;45:470-90.

30. Mugwagwa N, Mberikunashe J, Gombe NT, Tshimanga M, Bangure D, Mungati M. Factors associated with malaria infection in Honde valley, Mutasa district, Zimbabwe, 2014: a case control study. BMC Res Notes. 2015:8:829.

31. Macintyre K, Littrell M, Keating J, Hamainza B, Miller J, Eisele TP. Determinants of hanging and use of ITNs in the context of near universal coverage in Zambia. Health Policy Plan. 2012;27:316.

32. Pylypchuk $Y$, Norton SW. Preventing malaria among children in Zambia: the role of mother's knowledge. Health Econ. 2015;24:1389-402.

33. Winch PJ, Makemba AM, Kamazima SR, Lurie M, Lwihula GK, Premji Z, et al. Local terminology for febrile illnesses in Bagamoyo District, Tanzania and its impact on the design of a community-based malaria control programme. Soc Sci Med. 1996;42:1057-67.

34. Zimbabwe National Statistics Agency and ICF International. Zimbabwe Demographic and Health Survey 2015: final report. Rockville: Zimbabwe National Statistics Agency (ZIMSTAT) and ICF International; 2016.

35. Ministry of Health. Zambia national malaria indicator survey. Lusaka: Ministry of Health; 2015.

36. Worrall E, Basu S, Hanson K. Is malaria a disease of poverty? A review of the literature. Trop Med Int Health. 2005;10:1047-59.

37. Nankabirwa J, Brooker SJ, Clarke SE, Fernando D, Gitonga CW, Schellenberg D, et al. Malaria in school-age children in Africa: an increasingly important challenge. Trop Med Int Health. 2014;19:1294-309.

38. Walldorf JA, Cohee LM, Coalson JE, Bauleni A, Nkanaunena K, KapitoTembo A, et al. School-age children are a reservoir of malaria infection in Malawi. PLoS ONE. 2015;10:e0134061.

39. Launiala A. How much can a KAP survey tell us about people's knowledge, attitudes and practices? Some observations from medical anthropology research on malaria in pregnancy in Malawi. Anthropol Matters. 2009;11:1-13.

\section{Submit your next manuscript to BioMed Central and we will help you at every step:}

- We accept pre-submission inquiries

- Our selector tool helps you to find the most relevant journal

- We provide round the clock customer support

- Convenient online submission

- Thorough peer review

- Inclusion in PubMed and all major indexing services

- Maximum visibility for your research

Submit your manuscript at www.biomedcentral.com/submit
(OioMed Central 